\section{More calls for flexibility}

Tokyo

MuCH can be done to strengthen "bioscience" research in Japan, according to the Ministry of Education, Culture and Science (MESC)'s science council. A new series of measures to strengthen bioscience research in the univerisities was submitted to the minister last week.

The Science Council, consisting of 27 eminent scholars and scientists appointed by the ministry, is the central advisory body on scientific research policy in the universities. The report comes with the science council's official approval, but is actually the work of a 20 -member specialist subcommittee set up three years ago. It is expected to exert a considerable influence on MESC's grant policy and strengthen the position of the biosciences which here, despite an occasional nod towards neurobiology and its possible links with information technology, is taken to mean those sciences using the new techniques of molecular biology.

The report is wide in scope but does not, in its 19 pages, describe how specific proposals should be implemented: its more controversial, and expensive, suggestions are often given as "requiring debate". Overall the council took the modest view that bioscience education and research facilities lag behind those in Europe and the United States. A key point is that bioscience research is by its nature interdisciplinary and rapidly spawns applied technologies which in turn affect basic research. Thus it becomes essential to break down academic barriers - often strong in Japan where departments and the holders of chairs have considerable power and biosciences. autonomy. More cooperative research is called for both within the universities and between the universities, attached research institutes and joint-use institutes.

More efforts are needed to ensure adequate supply of research materials; MESC may set up a gene bank as well as computerized databases. More surveys of research trends, both home and abroad, are urged to spot important areas. Plant molecular biology is singled out as a field that has been slow to develop but is likely to be of great importance.

More fellowships for young people and a greater role in their training is urged for research institutes and the joint-use institutes: although the latter often have superior facilities, they have had less say in how graduates are to be trained. A possibility for the longer term is that of setting up a graduate university. More workshops, training and retraining courses are called for, as well as international exchange, both of researchers and of information.

Cooperation with industry is also recognized and a suggestion made that a joint research centre be set up.

Given that the report comes from MESC's key policy body it is likely to affect policy for some time to come and is very good news for molecular biologists. First effects are likely to be seen on grantsin-aid of research. Other effects - on the organization of courses and faculties for example - are likely to take place more slowly. But it is too early to know whether any new money will be made available to support an increased initiative in the

\title{
New research laws miss Nakasone's point
}

Tokyo

"SomE professors go on repeating the lectures they wrote in their youth until the day they retire", was how Japan's Prime Minister Yoshiro Nakasone uncharitably described university teachers last week. The remarks, prefaced by comments that the level of science in Japan's universities is lower than in the West, were made at a meeting of the House of Representatives budget committee. Nakasone followed up with a controversial suggestion, not unfamiliar to Western researchers, that tenure should be of short duration with evaluation every "five to ten years".

The total security enjoyed by university professors, employed as civil servants by the Ministry of Education, Culture and Science is in no imminent danger of being disturbed, however. Present legislative action to improve the research system is focused on government research institutes. $A$
US universities

\section{Academics fear budget cuts}

Washington

Closer reading of last month's budget seems to have alerted US academics to the seriousness of the consequences for higher education if the federal budget survives the next few months in its present form. Students will be especially badly hit.

The administration's proposals would reduce total spending on direct student support during the coming academic year from $\$ 4,860$ million to $\$ 3,840$ million. The funds available for Pell grants, which are awarded to students offered a place at a university and able to demonstrate financial need, has already been affected (to the tune of more than $\$ 100$ million) by the Gramm-Rudman law; it is now planned to save a further $\$ 359$ million by imposing a ceiling of $\$ 2,100$ on the value of an award during the coming academic year and by reducing the number of awards, from the 2.7 million now current to 2.1 million next year. A scheme for matching state funds used to make awards to needy students would be eliminated under the proposals.

The administration also proposes to reduce the cost of the student loan programme, but by reorganizing it along lines to be embodied in legislation not yet introduced. At present, the schemes function by the provision of federal subsidies and guarantees to lending institutions. The intention is to save about $\$ 1,000$ million a year by requiring that students should pay the full Treasury bill rate during the period of their studies and a higher rate thereafter, while the loan is outstanding.

Although the total amounts involved in institutional support are much smaller, they stand out in the budget proposals by the frequency with which the proposals would eliminate them altogether. Schemes for supporting graduate education, including the National Graduate Fellowships scheme, would be stopped, as would the small schemes for supporting academic libraries and international studies departments at US universities. The scheme for supporting younger institutions with federal grants, the chief source of federal support for university institutions, will remain at roughly the same level but its character will be recast by means of new legislation.

The American Council on Education, which is protesting at the budget resolutions, explains that the uncertainties of the budgetary process in the months ahead imply that it may be harder than in previous years to mobilize support in Congress when individual legislators cannot tell whether amendments to the budget proposals may damage the causes they are seeking to support. 